\title{
Article
}

\section{Filter Extracted Sliding Mode Approach for DC Microgrids}

\author{
Abdul Rehman Yasin ${ }^{1, *(\mathbb{D}}$, Amina Yasin ${ }^{2}{ }^{(}$, , Mudassar Riaz $^{1}{ }^{1}$, Muhammad Ehab $^{1}$ and Ali Raza ${ }^{3} \mathbb{C}$ \\ 1 Department of Electrical Engineering, The University of Lahore, Lahore 54000, Pakistan; \\ mudassarriaz041@gmail.com (M.R.); muhammad.ehab97@gmail.com (M.E.) \\ 2 Department of Basic Sciences, Preparatory Year Deanship, King Faisal University, \\ Al Hofuf 31982, Saudi Arabia; amnagyasin@gmail.com \\ 3 Department of Electrical, Electronics and Telecommunication Engineering, University of Engineering and \\ Technology, New Campus, Lahore 54000, Pakistan; a.raza@uet.edu.pk \\ * Correspondence: metary@gmail.com; Tel.: +92-321-4511396
}

Citation: Yasin, A.R.; Yasin, A.; Riaz, M.; Ehab, M.; Raza, A. Filter Extracted Sliding Mode Approach for DC Microgrids. Electronics 2021, 10, 1882. https://doi.org/10.3390/ electronics10161882

Academic Editor: Jesús C. Hernandez

Received: 16 June 2021

Accepted: 31 July 2021

Published: 5 August 2021

Publisher's Note: MDPI stays neutral with regard to jurisdictional claims in published maps and institutional affiliations.

Copyright: (c) 2021 by the authors. Licensee MDPI, Basel, Switzerland. This article is an open access article distributed under the terms and conditions of the Creative Commons Attribution (CC BY) license (https:// creativecommons.org/licenses/by/ $4.0 /)$.

\begin{abstract}
The advantages offered by DC microgrids, such as elimination of skin effect losses, no requirement of frequency synchronization and high efficiency for power transmission are the major reasons that microgrids have attracted the attention of researchers in the last decade. Moreover, the DC friendly nature of renewable energy resources makes them a perfect choice for integration with DC microgrids, resulting in increased reliability and improved stability. However, in order to integrate renewable energy resources with the DC microgrids, challenges like equal load sharing and voltage regulation of the busbar under diverse varying load conditions are to be addressed. Conventionally, droop control with PI compensation is used to serve this purpose. However, this cascaded scheme results in poor regulation to large load variations and steady state errors. To address this issue, this paper presents a sliding mode control-based approach. Key features of SMC are its ease of implementation, robustness to load variations, and fast dynamic response. The system model is derived and simulated to analyze the stability and performance of the proposed controller. An experimental test bench is developed to demonstrate the effectiveness of SMC against modeled dynamics and is compared with the droop controller. The results show an improvement of $26 \%$ and $27.4 \%$ in the rise time and settling time, respectively. Robustness of the proposed scheme is also tested by switching it with a step load and an improvement of $40 \%$ has been observed.
\end{abstract}

Keywords: droop control; sliding mode control; DC microgrid; load sharing; voltage regulation

\section{Introduction}

Due to the increased demand of electric power, the utilization of the fuel used for its generation has also significantly increased. The fuel commonly used for power generation is in the form of fossil fuels such as coal and petroleum, which has caused its rapid depletion and various other environmental concerns. This has motivated the scientists to integrate the renewable energy sources and reduce the transmission and distribution losses to fulfill the needs of the industry and society [1-3]. To maintain the balance of power between the supply and load, the coordination of these sources such as wind and solar along with their control is an essential part of a microgrid. A microgrid offers various benefits such as high reliability, low losses, enhanced adaptability and feasibility offered in terms of its implementation.

Most of our electronic loads such as frequency drives and LEDs operate on DC. Their operation from existing AC grids requires conversion from AC to DC. However, the output of renewable energy resources is mostly DC; conversion from $A C$ to $D C$ is required for their connection to AC microgrids [4,5]. Thus multiple conversions from DC-AC and AC-DC are needed for their integration in the power system which results in increased losses and low system efficiency.

Therefore, to minimize the conversion and distribution losses, DC systems are more preferred as they offer high efficiency as compared to AC systems [6-12]. Moreover in 
DC, skin effect is absent and it does not require additional reactive power compensation equipment or the synchronization of frequency. All these benefits make DC microgrids an attractive choice for integrating renewable sources with our electrical system [13-16].

Figure 1 shows the various sources and loads which are connected together forming a microgrid. Its generic structure is simple which allows the interconnection of sources within and with the main power grid. The sources and the storage devices are interconnected with the microgrid with the use of power electronic converters.

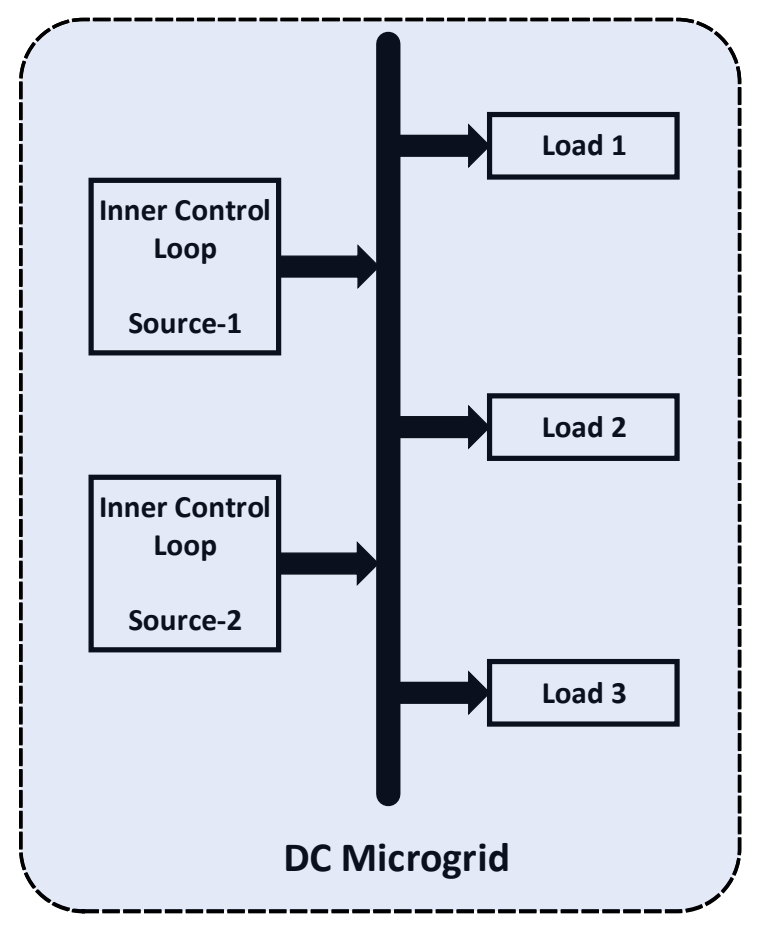

Figure 1. Block diagram showing structure of DC microgrid.

In [17-19], droop control is reported in AC microgrids due to its benefits such as low cost and easy implementation, which has inspired the researchers to use this method in DC microgrids [20-23].

However, droop control suffers from steady state errors to large droop gains which makes its use less feasible in the case of large load variations. To overcome this drawback, PI compensated droop control is used due to its ease of implementation and tuning methods. However, PI compensated droop controller suffers from steady state error and other issues like slower transient response and parameter dependency. The grid parameters are required to derive the controller gains. These parameters vary with the source and the load and thus they cannot ensure global stability as the operating conditions are constantly changing. Therefore, it is not feasible to use these techniques for voltage stability [24,25]. Furthermore, Fuzzy Logic Controllers [26-28] and auto-tuning methods [29] have also been proposed, but their implementation is relatively complex.

Different control schemes such as adaptive control [30,31], boundary layer control [32,33], model predictive control $[34,35]$ and time-delayed robust controller [36], have been utilized to achieve the desired performance. However, these techniques are parameter dependent. Therefore, there is a need for a robust controller which is able to regulate the grid voltages in the presence of varying load conditions.

To address this problem, a non-linear control technique based on Sliding Mode Control (SMC) is proposed in [37]. SMC is well known for its ability to control the non-linear dynamics in the presence of uncertain parameters and unmodeled dynamics. It offers advantages such as increased robustness, parameter invariance, order reduction and disturbance rejection $[38,39]$. Therefore it becomes a good candidate for the control of voltage and current in a DC microgrid [40-42]. However, its major drawback is its varying switching 
frequency which is a major requirement for power electronic converters. They need to operate at fixed frequency in order to minimize the switching losses and suppress Electromagnetic Interference (EMI) [43-47]. In [43], a new technique based on fixed frequency SMC has been proposed. This filter extracted method provides increased robustness and improved dynamic response in comparison with the previously mentioned techniques.

However, this method has only been implemented as a standalone application on a DC-DC converter and to the best of authors' knowledge, this technique has not been tested on position of a microgrid. This leads to the hypothesis of this research that filter extracted SMC will improve the dynamic response as well as the robustness when implemented on a microgrid. In this paper, a filter extracted fixed frequency sliding mode control with a centralized control system is proposed to track the grid voltages with improved dynamic response and robustness. The technique is implemented on a boost converter which in turn regulates and tracks the voltages of each source to ensure proper load sharing along with precise voltage regulation in the presence of unmodeled and uncertain load dynamics. Furthermore, a mathematical analysis is also presented to validate the stability of the controller. A complete comparison between the PI compensated droop controller and the proposed technique is presented. In order to validate the proposed control scheme, an experimental test rig with the parameters given in Table 1 is developed in which two separate grids are tested in the presence of a secondary controller. The results prove that the proposed technique performs better as compared to the PI compensated droop controller.

Table 1. Parameters of DC microgrid.

\begin{tabular}{lll}
\hline Description & Symbol & Value \\
\hline Input Voltage & $V_{\text {in }}$ & $12 \mathrm{~V}$ \\
Output Voltage & $V_{\text {out }}$ & $36 \mathrm{~V}$ \\
Capacitance & $C$ & $2200 \mu \mathrm{F}$ \\
Inductance of coil & $L$ & $130 \mu \mathrm{H}$ \\
Switching Frequency & $f_{s w}$ & $38 \mathrm{kHz}$ \\
Load Resistance & $R_{L}$ & $50-150$ \\
\hline
\end{tabular}

\section{Control Architectures}

A microgrid provides the coordination between the source and the load. A DC microgrid can be implemented using either a centralized or a decentralized control strategy.

\subsection{Decentralized Control}

A decentralized control scheme is usually implemented using droop control due to its benefits such as easy implementation and low cost. This section describes the details of a conventional droop control system so that the proposed technique can be compared with the existing one. In the conventional design, the droop control parameters are set such that the system voltage is kept constant within the desired limits. A virtual droop resistance is a non-physical entity which is added into the system to ensure equal load sharing. Mathematically the system is expressed as:

$$
v_{d c j}=v_{d c}^{*}-i_{j} R_{d j} ; \quad j=1,2
$$

where $v_{d c j}, v_{d c}^{*}, i_{j}$ and $R_{d j}$ are the node voltages, voltage reference, source current and the virtual resistance, respectively. Figure 2 shows a DC microgrid model consisting of two sources and two loads and its equivalent thevenin model. Applying KVL and KCL to Figure 2, we get:

$$
\frac{i_{1}}{i_{2}}=\frac{R_{d 2}}{R_{d 1}+R_{\text {line }}}
$$

where $R_{d 1}$ and $R_{d 2}$ denote the virtual resistances of source 1 and source 2 respectively. Equation (2) shows that the current of the sources is inversely proportional to their virtual 
resistance. Normally, it is idealized that a DC microgrid is of a small scale and therefore its connecting line will have a resistance of a negligible value. Therefore, its virtual resistance $R_{d j}$ can be selected of a large value. As $R_{d j}>>R_{l i n e}$, Equation (2) can be modified as:

$$
\frac{i_{1}}{i_{2}}=\frac{R_{d 2}}{R_{d 1}+R_{\text {line }}} \approx \frac{R_{d 2}}{R_{d 1}}
$$

However, this is only valid in the case of a small DC microgrid. In case of a large microgrid, Equation (2) cannot be satisfied. Apart from that, a large virtual resistance cannot ensure stability of the system.

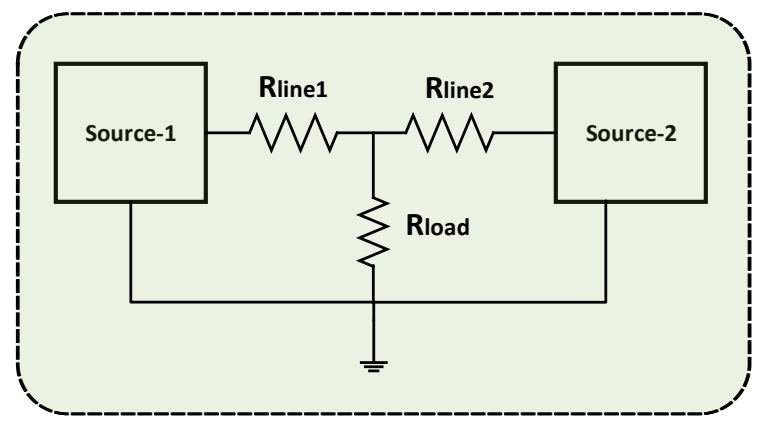

Figure 2. DC microgrid model consisting of two sources feeding a single load along with its equivalent Thevenin model.

The voltage deviation is given by:

$$
\Delta v_{d c j}=i_{j} R_{d j} \quad ; \quad j=1,2
$$

The voltage deviation can be limited by applying the following condition:

$$
R_{d j} \leqslant \frac{\Delta v_{d c \max }}{i_{f l j}}
$$

The output voltages of parallel connected power electronic converters are not exactly equal due to the presence of parasitic resistances and manufacturing tolerances of different components. Therefore, the droop gains must be selected such that it satisfies the desired requirements. For the case of small droop gain where multiple sources are connected to the same grid, a small change in the output voltage of one converter results in a large deviation of its source current. However, the increased droop gain results in large voltage variation which is not acceptable. Therefore, droop control suffers from steady state error. This issue is resolved by cascading PI controllers in the system which results in the PI compensated droop controller. The detailed discussion and implementation details are given in $[9,10]$. It offers various benefits such as low cost and ease of implementation. However, it results in slower transient response and requires periodic tuning.

\subsection{Centralized Control}

Figure 3 presents the centralized control scheme for the DC microgrid. A primary droop and inner current and voltage loops collectively constitute the controller. These primary controllers are associated with each power electronic converter. A centralized secondary architecture is designed to control these primary controllers. This secondary control provides the reference to each converter of the microgrid. Therefore, low voltage regulation is achieved using this scheme. Furthermore, distributed control ensures that any malfunction does not degrade system performance. 


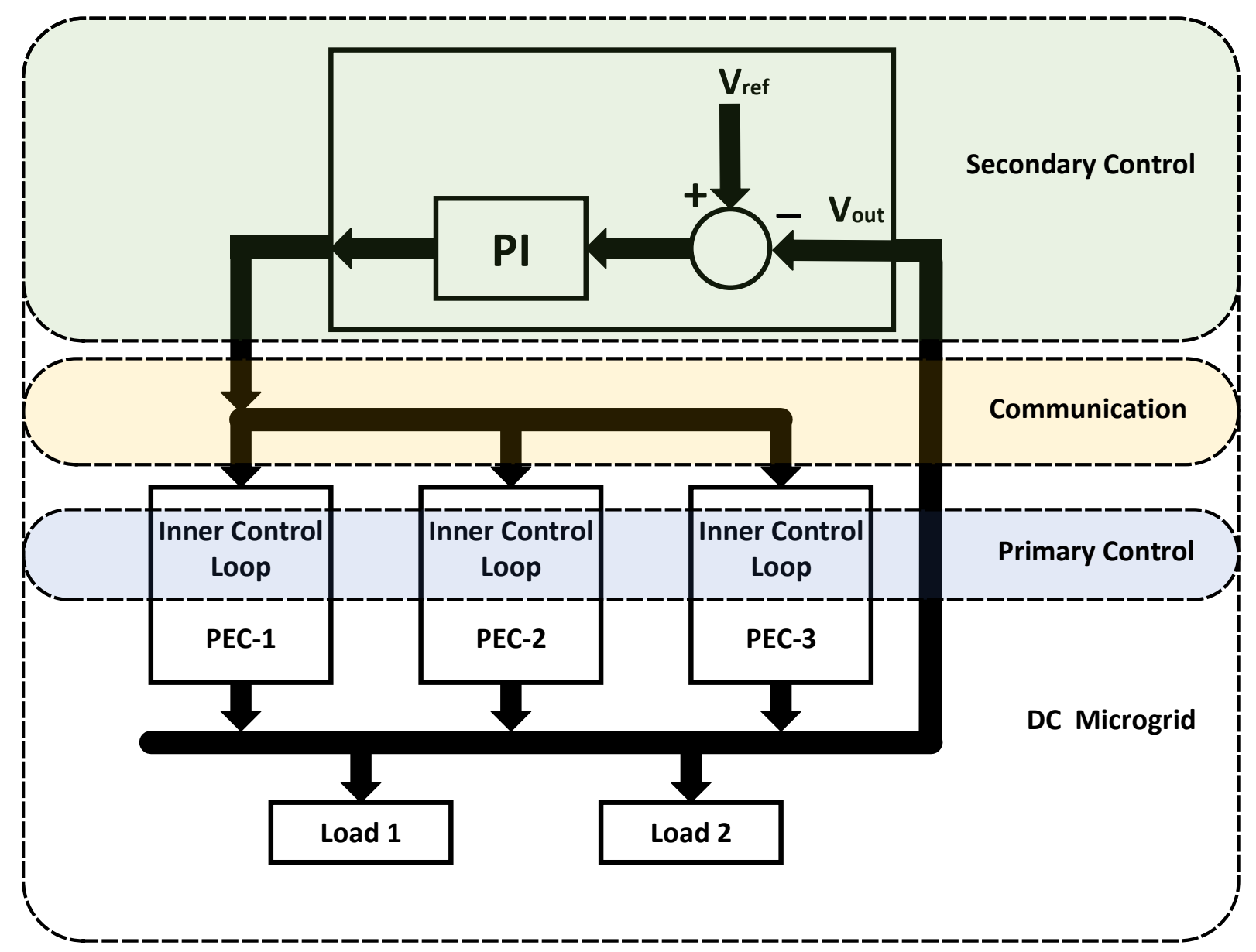

Figure 3. Centralized control scheme for DC microgrid.

\section{Proposed Controller}

The proposed technique deploys filter extracted fixed frequency SMC in the inner loop controlling the inductor current. Each source in grid structure consists of a DC-DC boost converter. The input to each source is provided through renewable energy resources. Boost converters, being non-minimum phase systems, cannot be controlled by acquiring only voltage feedback from the system. The dynamics of inductor current are much faster as compared to capacitor voltage. Therefore, this issue can be solved by utilizing two control loops in a cascaded control scheme. The dynamics of the inner loop are much faster than the outer loop and is an application of the singular perturbation theory.

Taking inductor current $I_{L}$ and output voltage $V_{\text {out }}$ as state-space variables, the mathematical model of the system is derived as:

$$
\begin{gathered}
\dot{x_{1}}=\frac{V_{\text {in }}}{L}-\tilde{\mu} \frac{V_{\text {out }}}{L} \\
\dot{x_{2}}=\tilde{\mu} \frac{I_{L}}{C}-\frac{V_{\text {out }}}{R C}
\end{gathered}
$$

where $V_{\text {in }}$ is the input voltage, $\mu$ is the control input which can either be ON or OFF and $\tilde{\mu}$ is its complement given by $\tilde{\mu}=1-\mu$. Moreover, $L$ is the inductance of the coil, $C$ is 
the capacitance of the output filter capacitor and $R$ is the load resistance. The switching function is given by Equation (8):

$$
\mu= \begin{cases}1, & \text { when pulse is high } \\ 0, & \text { when pulse is low }\end{cases}
$$

SMC is a non-linear control technique and its main benefits are increased robustness, reliability, order reduction and disturbance rejection. In addition to that, it is also parameter invariant. A sliding surface is designed such that the control law forces the system state variables to slide on the sliding manifold until the system reaches steady state condition. Based on the current error, the sliding surface $\sigma$ is selected as:

$$
\sigma=I_{r e f}-I_{L}
$$

where $I_{r e f}$ is constant which determines the reference value of inductor current. The control law that ensures to bound the inductor current $I_{L}$ on the sliding surface is given by:

$$
\mu=\frac{1}{2}(1+\operatorname{sign}(\sigma))
$$

Differentiating both sides of Equation (9) gives:

$$
\dot{\sigma}=-\dot{I_{L}}
$$

Substituting Equation (6) in (11) gives:

$$
\dot{\sigma}=\tilde{\mu} \frac{V_{\text {out }}}{L}-\frac{V_{\text {in }}}{L}
$$

As $\tilde{\mu}=1-\mu$ and $\mu=\frac{1}{2}(1+\operatorname{sign}(\sigma))$, so $\tilde{\mu}=\frac{1}{2}-\frac{1}{2} \operatorname{sign}(\sigma)$. Hence Equation (12) can be written as:

$$
\dot{\sigma}=\frac{V_{\text {out }}}{2 L}-\frac{V_{\text {out }}}{2 L} \operatorname{sign}(\sigma)-\frac{V_{\text {in }}}{L}
$$

The sliding surface $\sigma$ can only be converged to zero if and only if the convergence condition satisfies. The convergence condition is given by:

$$
\sigma \dot{\sigma}<0
$$

The above Equation (14) must hold for positive as well as negative values of $\sigma$. The proof of each quantity is discussed in following cases.

Case 1: When $\sigma \rightarrow 0^{+}$

For $\sigma$ being positive, its value gives +1 . Substituting the value of $\operatorname{sign}(\sigma)$ in Equation (13) gives:

$$
\begin{gathered}
\dot{\sigma}=\frac{V_{\text {out }}}{2 L}-\frac{V_{\text {out }}}{2 L}-\frac{V_{\text {in }}}{L} \\
\dot{\sigma}=-\frac{V_{\text {in }}}{L}
\end{gathered}
$$

So when $\sigma$ is positive, $\dot{\sigma}$ is negative. Hence Equation (14) holds for positive values of $\sigma$. When $\sigma \rightarrow 0^{-}$

For negative values of $\sigma$, we get -1 . Substituting the value of $\operatorname{sign}(\sigma)$ in (13) gives:

$$
\begin{gathered}
\dot{\sigma}=\frac{V_{\text {out }}}{2 L}+\frac{V_{\text {out }}}{2 L}-\frac{V_{\text {in }}}{L} \\
\dot{\sigma}=\frac{V_{\text {out }}}{L}-\frac{V_{\text {in }}}{L}
\end{gathered}
$$


For $V_{\text {out }}>V_{\text {in }}, \dot{\sigma}$ becomes positive for negative values of $\sigma$. Hence Equation (14) also holds for negative values of $\sigma$. It can therefore, be concluded that the sliding surface $\sigma$ is stable as it satisfies convergence condition of Equation (14). The actual inductor current at desired voltage $V_{d}$ can be derived from Equations (6) and (7) by putting the rate of change of output voltage $\dot{V}_{\text {out }}$ as well as the rate of change of inductor current $\dot{I}_{L}$ equal to zero. Hence, the equilibrium point current $I_{L}^{*}$ is presented as:

$$
I_{L}^{*}=\frac{V_{d}^{2}}{V_{i n} R}
$$

This paper incorporates the use of a low pass RC filter whose time constant is given by $\tau=R C$, where $\mathrm{R}$ and $\mathrm{C}$ denote the resistance and capacitance of the electronic filter. After applying KVL, we get the following relationship:

$$
\begin{aligned}
\mu & =R i(t)+v(t)=R C \frac{d v(t)}{d t}+v(t) \\
& =\tau \frac{d v(t)}{d t}+v(t)
\end{aligned}
$$

Here the filter capacitor instantaneous current is given by $i(t)$. As reported in $[38,43]$ the filter provides the equivalent control under the following condition:

$$
\lim _{\tau \rightarrow 0, f \rightarrow \infty} v(t)=\mu_{\text {eq }}
$$

Here $f$ denotes the switching frequency. It is observed that the state motion becomes nearly ideal SMC when the frequency increases and the width $\Delta$ of the state oscillations approach zero. This is shown that when $f \rightarrow \infty$ the $\Delta \rightarrow 0$. To filter out the high frequency components and extract $\mu_{e q}$, the switching frequency must follow the condition $f \gg \frac{1}{\tau}$.

The duty cycle of the power electronic converter is denoted by $k$. The equation $\mu_{e q}=k$ is responsible for the development and implementation of duty cycle based sliding mode approach $[48,49]$. After extracting $\mu_{\text {eq }}$, the control signal is derived as:

$$
\mu_{\text {eq }}=k=\frac{V_{\text {control }}}{V_{\text {ramp }}}
$$

where $V_{\text {ramp }}$ is the voltage of the ramp signal. This switching sequence results in the fixed frequency operation of the controller. This sequence is responsible for the operation of fixed frequency SMC.

\section{Results and Discussion}

The experimental setup is shown in Figure 4 and all the component parameters are mentioned in Table 1. The inductor coil is wound on an inductor core with a wire of 17 AWG having a diameter of 0.056 inch. The switch used is a power MOSFET IRF540 which has a maximum current capability of $20 \mathrm{~A}$. The capacitor is of a polarized type having a capacitance of $2200 \mu \mathrm{F}$. The converter is operated at a switching frequency of $38 \mathrm{kHz}$. Analog controller is used to realize both the inner and outer loops.

Droop control suffers from steady state error when applied in DC microgrids. Therefore, to validate the control technique, the proposed controller is implemented on hardware. For the sake of comparison, PI compensated droop controller is also implemented and results are compared with the proposed technique. Figure 5 shows the circuit diagram of the PI controller while the parameters are listed in Table 2. Ziegler Nichols Method has been used to obtain a well tunned response. Better results validate the superior performance of the proposed technique. Both the controllers provide an output of $36 \mathrm{~V}$ and thus exhibit zero steady state error as shown in Figure 6a. The gating sequence responsible 
for switching action given to the power electronic converter is shown in the Figure $6 \mathrm{~b}$. The steady state error is shown in the Figure 6c.

The controllers are also observed for their transient response by switching the inputs at $0.4 \mathrm{~Hz}$. This operation is achieved through RIGOL function generator. A switching circuit is also employed to connect and disconnect the input in which the signal from the function generator is given as input to a NPN transistor C1383 which in turn operates the PNP transistor TIP147. From the experiments, the rise time and settling time of the PI compensated droop control to be $50 \mathrm{~ms}$ and $113 \mathrm{~ms}$, respectively, as shown in Figure 7a. The response of the proposed controller is found out to be $37 \mathrm{~ms}$ and $82 \mathrm{~ms}$ respectively, shown in Figure $7 \mathrm{~b}$. The results show an improvement of $26 \%$ and $27.4 \%$ in the rise time and settling time respectively, thus validating the fact that the equivalent control is evaluated through the discontinuous function and no external methodology is used for its computation.

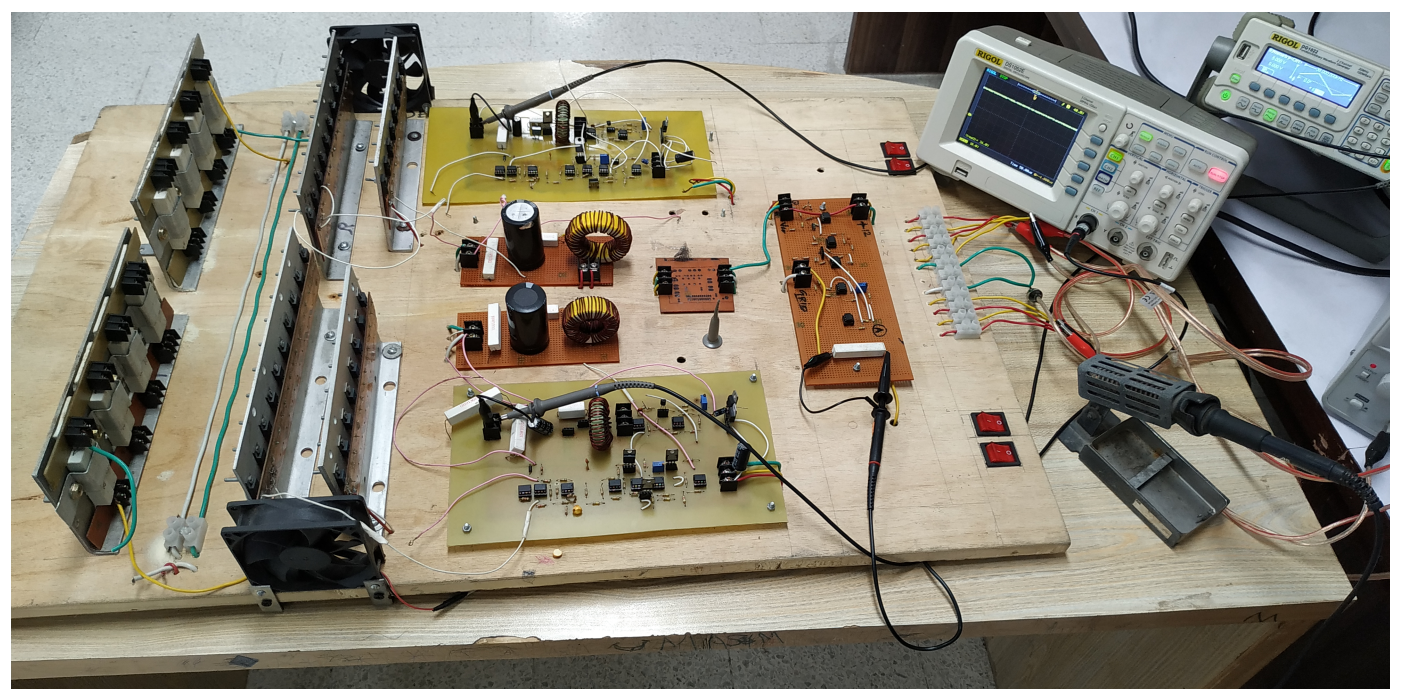

Figure 4. Experimental setup of the proposed controller.

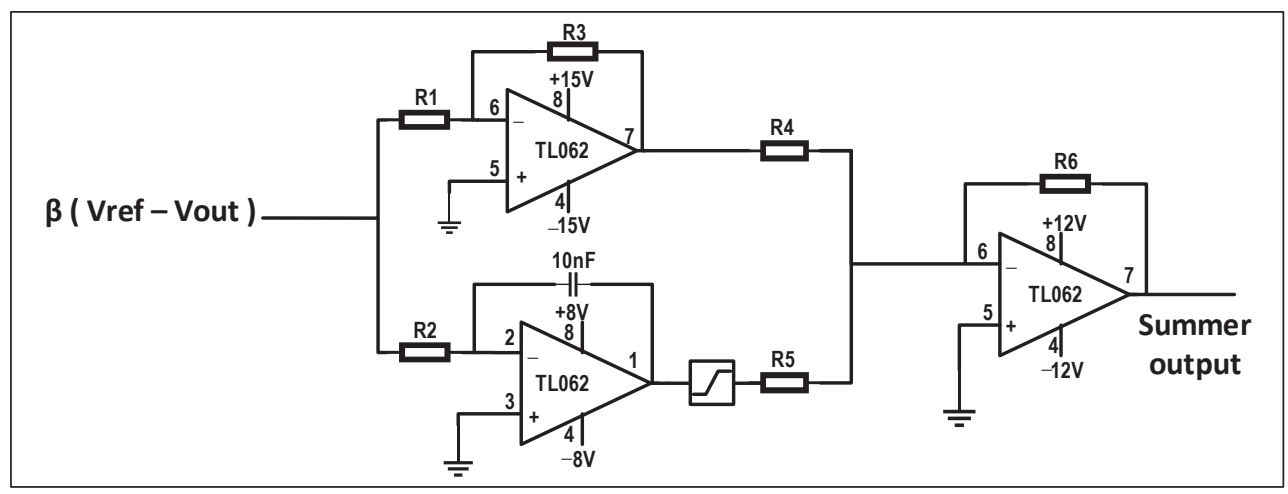

Figure 5. Electronic circuit used for PI controller. 
Table 2. Value of resistances.

\begin{tabular}{ccc}
\hline Sr. & Resistances & Values \\
\hline 1 & R1 & $1.2 \mathrm{~K}$ \\
\hline 2 & R2 & $22 \mathrm{~K}$ \\
\hline 3 & $\mathrm{R} 3$ & $8.2 \mathrm{~K}$ \\
\hline 4 & $\mathrm{R} 4$ & $10 \mathrm{~K}$ \\
\hline 5 & $\mathrm{R} 5$ & $10 \mathrm{~K}$ \\
\hline 6 & $\mathrm{R} 6$ & $10 \mathrm{~K}$ \\
\hline 7 & $\beta$ & 0.103 \\
\hline
\end{tabular}

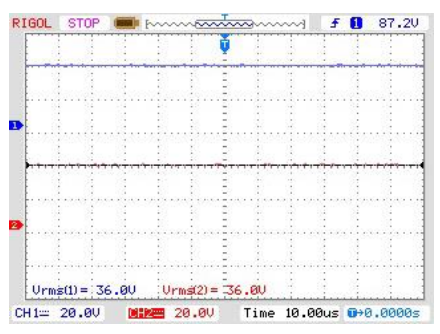

(a)

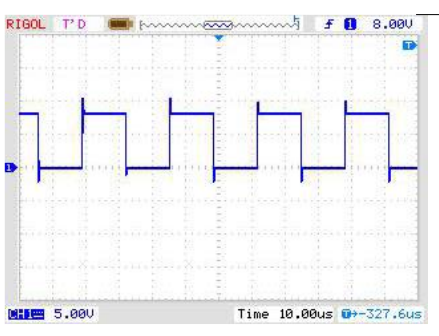

(b)

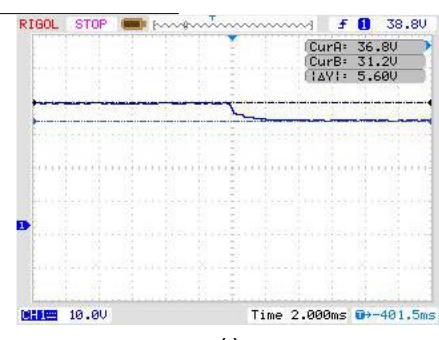

(c)

Figure 6. (a) Output voltages of the DC microgrid. (b) Gating sequence given to the power converter. (c) Steady state error occuring in a DC microgrid during droop operation.

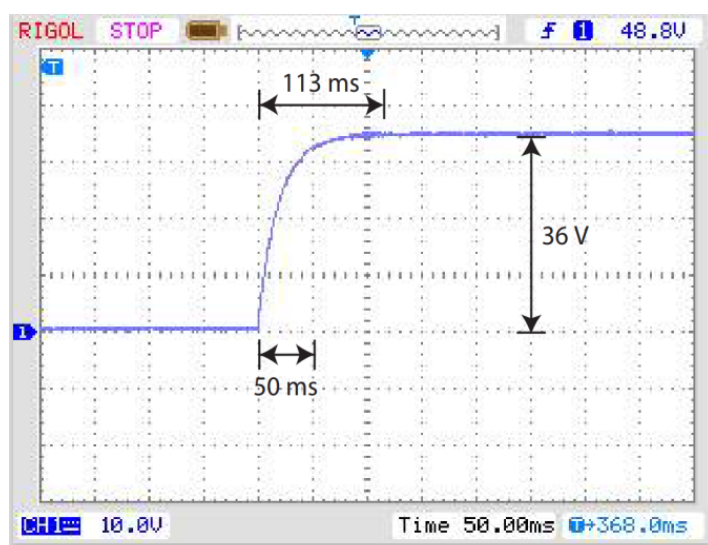

(a)

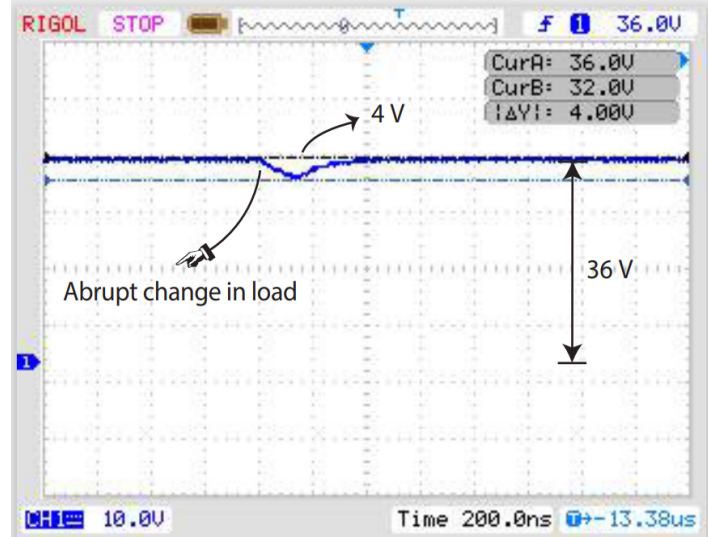

(c)

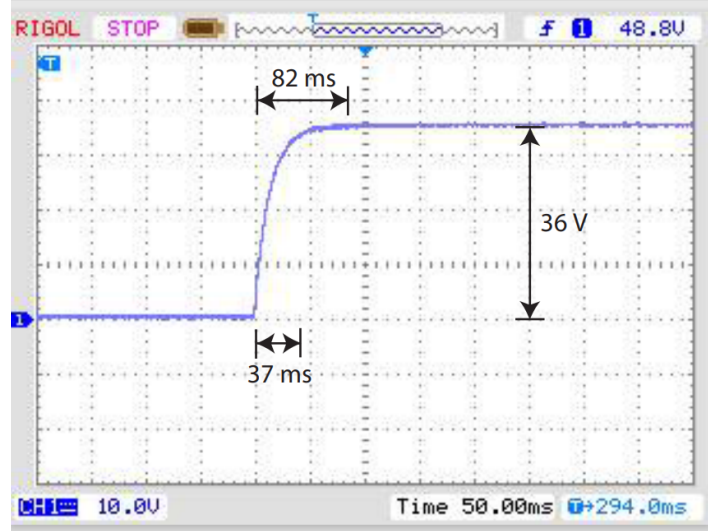

(b)

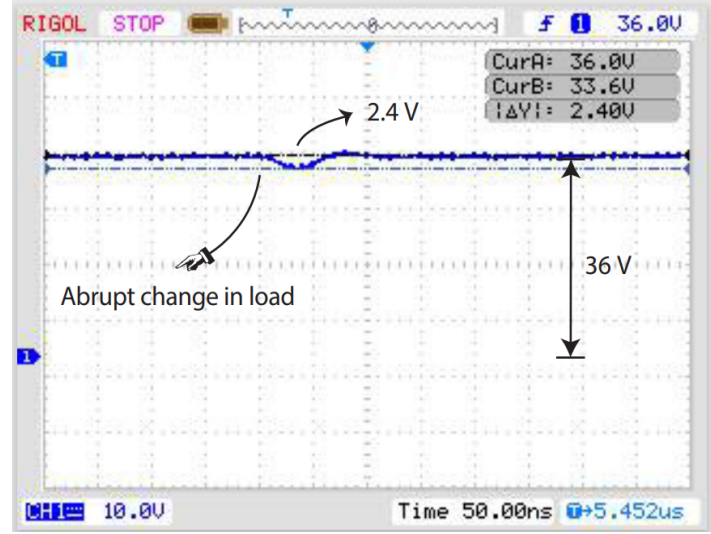

(d)

Figure 7. (a) Step response of PI compensated droop controller. (b) Step response of the proposed controller. (c) Voltage dip observed while connecting a resistance of $56 \Omega$ in parallel to the existing $100 \Omega$ in the PI compensated droop controller. (d) Voltage dip observed while connecting a resistance of $56 \Omega$ in parallel to the existing $100 \Omega$ in the proposed controller. 
In order to justify the robustness of the controllers, the load resistance is abruptly increased. An additional circuit is used to connect a resistance of $56 \Omega$ in parallel with the existing $100 \Omega$. The voltage dip of PI compensated droop controller as shown in Figure $7 \mathrm{c}$ is observed to be $4 \mathrm{~V}$ thus resulting in an improvement of $40 \%$ where the dip of the proposed controller is only $2.4 \mathrm{~V}$ as presented in Figure $7 \mathrm{~d}$. Furthermore, the PI compensated droop controller recovers in $375 \mathrm{~ns}$ while the proposed controller recovers in $130 \mathrm{~ns}$, resulting in an improvement of $65.3 \%$ in the recovery time.

When tested on a scaled-down micro grid with two sources and a single load, it was determined that the technique was capable of regulating a DC micro grid. An external control loop generates a reference current signal for each of the proposed controller's sources, which the proposed controller can utilize. The currents of each source are represented in Figure 8 during the feeding of a $62 \Omega$ load having $5 \%$ tolerance. Source 1 supplies $291 \mathrm{~mA}$ of current, whereas Source 2 supplies $292 \mathrm{~mA}$. With a load sharing error of less than $1 \%$, the proposed technique is capable of maintaining the specified grid voltage.

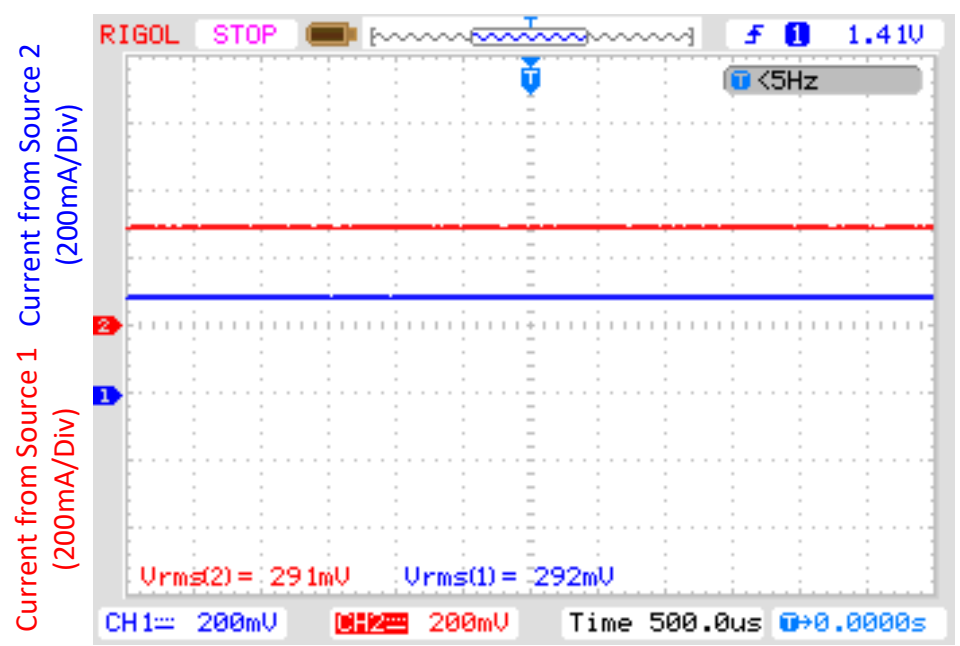

Figure 8. Current sharing of two sources in micro-grid operation using the purposed technique.

\section{Conclusions}

This manuscript presents a fixed extracted equivalent control-based fixed frequency SMC for precise voltage regulation and load sharing in DC microgrids. The controller is implemented and experimental results prove the hypothesis that filter extracted SMC greatly enhances the dynamic response as well as improves the robustness of the system to load variations and input fluctuations when applied to DC microgrids. A detailed section on the derivation of the stability of the sliding surface, parameterization of the controller and its hardware design is also presented. The controller is realized using commercially available analogue ICs and components thus eliminating the need for FPGA and DSP boards which add additional cost to the system design. To compare the performance of the proposed controller, PI compensated droop controller is also implemented. Test results reveal that the filter extracted SMC improves the rise time and settling time of the controller by $26 \%$ and $27.4 \%$, respectively. A voltage dip is observed on the controllers when an abrupt additional load is applied on the system. This voltage sag is reduced by $40 \%$ by the proposed technique as compared to the PI compensated droop controller.

Author Contributions: A.R.Y. provided the conceptualization and supervised the project. A.Y., M.R., M.E. and A.R. developed the methodology for the investigation and performed formal analysis. All authors have read and agreed to the published version of the manuscript.

Funding: This research received no external funding.

Conflicts of Interest: The authors declare no conflict of interest. 


\section{References}

1. Akeyo, O.M.; Patrick, A.; Ionel, D.M. Study of Renewable Energy Penetration on a Benchmark Generation and Transmission System. Energies 2021, 14, 169. [CrossRef]

2. Ahmed, D.; Ebeed, M.; Ali, A.; Alghamdi, A.S.; Kamel, S. Multi-objective energy management of a micro-grid considering stochastic nature of load and renewable energy resources. Electronics 2021, 10, 403. [CrossRef]

3. Ma, J.; Zhang, S.; Li, X.; Du, D. Integrating base-load cycling capacity margin in generation capacity planning of power systems with high share of renewables. Trans. Inst. Meas. Control. 2019, 42, 31-41. [CrossRef]

4. Anand, S.; Fernandes, B. Optimal voltage level for DC microgrids. In Proceedings of the IECON 2010-36th Annual Conference on IEEE Industrial Electronics Society, Glendale, AZ, USA, 7-10 November 2010; pp. 3034-3039.

5. Affam, A.; Buswig, Y.M.; Othman, A.K.B.H.; Julai, N.B.; Qays, O. A review of multiple input DC-DC converter topologies linked with hybrid electric vehicles and renewable energy systems. Renew. Sustain. Energy Rev. 2021, 135, 110186. [CrossRef]

6. Ghorbal, M.J.B.; Moussa, S.; Ziani, J.A.; Slama-Belkhodja, I. A comparison study of two DC microgrid controls for a fast and stable DC bus voltage. Math. Comput. Simul. 2021, 184, 210-224. [CrossRef]

7. Esmaeli, A. Stability Analysis and Control of Microgrids by Sliding Mode Control (Retraction of Vol 78, Pg 22, 2016); Elsevier Science Ltd.: Oxford, UK, 2017

8. Ali, A.I.M.; Sayed, M.A.; Takeshita, T. Isolated single-phase single-stage DC-AC cascaded transformer-based multilevel inverter for stand-alone and grid-tied applications. Int. J. Electr. Power Energy Syst. 2021, 125, 106534. [CrossRef]

9. Jin, C.; Wang, P.; Xiao, J.; Tang, Y.; Choo, F.H. Implementation of hierarchical control in DC microgrids. IEEE Trans. Ind. Electron. 2013, 61, 4032-4042. [CrossRef]

10. Anand, S.; Fernandes, B.G.; Guerrero, J. Distributed control to ensure proportional load sharing and improve voltage regulation in low-voltage DC microgrids. IEEE Trans. Power Electron. 2012, 28, 1900-1913. [CrossRef]

11. Guerrero, J.M.; Vasquez, J.C.; Matas, J.; De Vicuña, L.G.; Castilla, M. Hierarchical control of droop-controlled AC and DC microgrids-A general approach toward standardization. IEEE Trans. Ind. Electron. 2010, 58, 158-172. [CrossRef]

12. Kakigano, H.; Miura, Y.; Ise, T. Low-voltage bipolar-type DC microgrid for super high quality distribution. IEEE Trans. Power Electron. 2010, 25, 3066-3075. [CrossRef]

13. Rahimi, R.; Habibi, S.; Shamsi, P.; Ferdowsi, M. A Dual-Switch Coupled Inductor-Based High Step-Up DC-DC Converter for Photovoltaic-Based Renewable Energy Applications. In Proceedings of the 2021 IEEE Texas Power and Energy Conference (TPEC), College Station, TX, USA, 2-5 February 2021; pp. 1-6.

14. Fathima, H.; Prabaharan, N.; Palanisamy, K.; Kalam, A.; Mekhilef, S.; Justo, J.J. Hybrid-Renewable Energy Systems in Microgrids: Integration, Developments and Control; Woodhead Publishing: Southston, UK, 2018.

15. Moazzami, M.; Moradi, J.; Shahinzadeh, H.; Gharehpetian, G.B.; Mogoei, H. Optimal Economic Operation of Microgrids Integrating Wind Farms and Advanced Rail Energy Storage System. Int. J. Renew. Energy Res. (IJRER) 2018, 8, 1155-1164.

16. Adefarati, T.; Bansal, R. Reliability, economic and environmental analysis of a microgrid system in the presence of renewable energy resources. Appl. Energy 2019, 236, 1089-1114. [CrossRef]

17. Xing, W.; Wang, H.; Lu, L.; Wang, S.; Ouyang, M. An adaptive droop control for distributed battery energy storage systems in microgrids with DAB converters. Int. J. Electr. Power Energy Syst. 2021, 130, 106944. [CrossRef]

18. Golsorkhi, M.S.; Shafiee, Q.; Lu, D.D.C.; Guerrero, J.M. Distributed Control of Low-Voltage Resistive AC Microgrids. IEEE Trans. Energy Convers. 2018, 34, 573-584. [CrossRef]

19. Rocabert, J.; Luna, A.; Blaabjerg, F.; Rodriguez, P. Control of power converters in AC microgrids. IEEE Trans. Power Electron. 2012, 27, 4734-4749. [CrossRef]

20. Shi, J.; Yue, D.; Weng, S. Distributed event-triggered mechanism for secondary voltage control with microgrids. Trans. Inst. Meas. Control 2019, 41, 1553-1561. [CrossRef]

21. Khorsandi, A.; Ashourloo, M.; Mokhtari, H.; Iravani, R. Automatic droop control for a low voltage DC microgrid. IET Gener. Transm. Distrib. 2016, 10, 41-47. [CrossRef]

22. Vu, T.V.; Perkins, D.; Diaz, F.; Gonsoulin, D.; Edrington, C.S.; El-Mezyani, T. Robust adaptive droop control for DC microgrids. Electr. Power Syst. Res. 2017, 146, 95-106. [CrossRef]

23. Peyghami, S.; Davari, P.; Mokhtari, H.; Blaabjerg, F. Decentralized Droop Control in DC Microgrids Based on a Frequency Injection Approach. IEEE Trans. Smart Grid 2019, 10, 6782-6791. [CrossRef]

24. Mahmoodi, M.; Gharehpetian, G.; Abedi, M.; Noroozian, R. Control systems for independent operation of parallel dg units in dc distribution systems. In Proceedings of the 2006 IEEE International Power and Energy Conference, Putra Jaya, Malaysia, 28-29 November 2006; pp. 220-224.

25. Karlsson, P. DC Distributed Power Systems. Analysis, Design and Control for a Renewable Energy System. Ph.D. Thesis, Department of Industrial Electrical Engineering and Automation, Lund University, Lund, Sweden, 2002.

26. Ali, M.N.; Mahmoud, K.; Lehtonen, M.; Darwish, M.M. Promising MPPT Methods Combining Metaheuristic, Fuzzy-Logic and ANN Techniques for Grid-Connected Photovoltaic. Sensors 2021, 21, 1244. [CrossRef]

27. Lee, M.; Chen, D.; Huang, K.; Liu, C.W.; Tai, B. Modeling and design for a novel adaptive voltage positioning (AVP) scheme for multiphase VRMs. IEEE Trans. Power Electron. 2008, 23, 1733-1742. [CrossRef]

28. Guo, L.; Hung, J.Y.; Nelms, R.M. Evaluation of DSP-based PID and fuzzy controllers for DC-DC converters. IEEE Trans. Ind. Electron. 2009, 56, 2237-2248. 
29. Shirazi, M.; Zane, R.; Maksimovic, D. An autotuning digital controller for DC-DC power converters based on online frequencyresponse measurement. IEEE Trans. Power Electron. 2009, 24, 2578-2588. [CrossRef]

30. Rey-Boué, A.B.; Guerrero-Rodríguez, N.; Stöckl, J.; Strasser, T.I. Frequency-adaptive control of a three-phase single-stage grid-connected photovoltaic system under grid voltage sags. Int. J. Electr. Power Energy Syst. 2021, 125, 106416. [CrossRef]

31. Linares-Flores, J.; Méndez, A.H.; García-Rodríguez, C.; Sira-Ramírez, H. Robust nonlinear adaptive control of a "boost" converter via algebraic parameter identification. IEEE Trans. Ind. Electron. 2013, 61, 4105-4114. [CrossRef]

32. Kirshenboim, O.; Peretz, M.M. Stability analysis of boundary and hybrid controllers for indirect energy transfer converters. IEEE Trans. Power Electron. 2015, 31, 3360-3371. [CrossRef]

33. Sami, I.; Ullah, S.; Ullah, N.; Ro, J.S. Sensorless fractional order composite sliding mode control design for wind generation system. ISA Trans. 2021, 111, 275-289. [CrossRef] [PubMed]

34. Nam, N.N.N.; Nguyen, N.D.; Yoon, C.; Choi, M.; Lee, Y.I. Voltage sensorless model predictive control for a grid-connected inverter with LCL filter. IEEE Trans. Ind. Electron. 2021. [CrossRef]

35. Cavanini, L.; Cimini, G.; Ippoliti, G.; Bemporad, A. Model predictive control for pre-compensated voltage mode controlled DC-DC converters. IET Control Theory Appl. 2017, 11, 2514-2520. [CrossRef]

36. Wang, Y.X.; Yu, D.H.; Kim, Y.B. Robust time-delay control for the DC-DC boost converter. IEEE Trans. Ind. Electron. 2013, 61, 4829-4837. [CrossRef]

37. Rashad, M.; Ashraf, M.; Bhatti, A.I.; Minhas, D.M. Mathematical modeling and stability analysis of DC microgrid using SM hysteresis controller. Int. J. Electr. Power Energy Syst. 2018, 95, 507-522. [CrossRef]

38. Utkin, V.; Guldner, J.; Shi, J. Sliding Mode Control in Electro-Mechanical Systems; CRC Press: Boca Raton, FL, USA, 2009.

39. Edwards, C.; Spurgeon, S. Sliding Mode Control: Theory and Applications; CRC Press: Boca Raton, FL, USA, 1998.

40. Baghaee, H.R.; Mirsalim, M.; Gharehpetian, G.B.; Talebi, H.A. A decentralized power management and sliding mode control strategy for hybrid AC/DC microgrids including renewable energy resources. IEEE Trans. Ind. Inform. 2017. [CrossRef]

41. Cucuzzella, M.; Lazzari, R.; Trip, S.; Rosti, S.; Sandroni, C.; Ferrara, A. Sliding mode voltage control of boost converters in DC microgrids. Control Eng. Pract. 2018, 73, 161-170. [CrossRef]

42. Yasin, A.R.; Ashraf, M.; Bhatti, A.I.; Uppal, A.A. Fixed frequency sliding mode control of renewable energy resources in DC micro grid. Asian J. Control. 2019, 21, 2074-2086. [CrossRef]

43. Yasin, A.R.; Ashraf, M.; Bhatti, A.I. A Novel Filter Extracted Equivalent Control Based Fixed Frequency Sliding Mode Approach for Power Electronic Converters. Energies 2019, 12, 853. [CrossRef]

44. Yasin, A.; Ashraf, M.; Bhatti, A. Fixed frequency sliding mode control of power converters for improved dynamic response in DC micro-grids. Energies 2018, 11, 2799. [CrossRef]

45. He, Y.; Luo, F. Sliding-mode control for dc-dc converters with constant switching frequency. IEE Proc.-Control Theory Appl. 2006, 153, 37-45. [CrossRef]

46. Abeywardana, D.B.W.; Hredzak, B.; Agelidis, V.G. A fixed-frequency sliding mode controller for a boost-inverter-based battery-supercapacitor hybrid energy storage system. IEEE Trans. Power Electron. 2016, 32, 668-680. [CrossRef]

47. Gao, M.; Wang, D.; Li, Y.; Yuan, T. Fixed frequency pulse-width modulation based integrated sliding mode controller for phase-shifted full-bridge converters. IEEE Access 2017, 6, 2181-2192. [CrossRef]

48. Sira-Ramirez, H.J.; Ilic, M. A geometric approach to the feedback control of switch mode DC-to-DC power supplies. IEEE Trans. Circuits Syst. 1988, 35, 1291-1298. [CrossRef]

49. Morel, C.; Guignard, J.C.; Guillet, M. Sliding mode control of DC-to-DC power converters. In Proceedings of the IEEE 9th International Conference on Electronics, Circuits and Systems, Dubrovnik, Croatia, 15-18 September 2002; Volume 3, pp. 971-974. 